\title{
Donor (HO-) and Acceptor (Nitro-) Substituted BODIPY as a Solvent Turn-on Fluorescence Dye
}

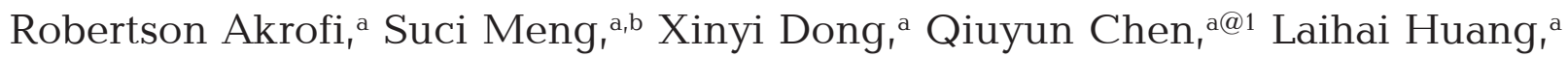 \\ Yuanyuan Fang, ${ }^{a}$ Lingling $\mathrm{Qu}^{\mathrm{a}}{ }^{\mathrm{a}}$ and Xu Liang ${ }^{\mathrm{a}} 2$ \\ a School of the Environment and Safety Engineering, School of Chemistry and Chemical Engineering, Jiangsu University, \\ Zhenjiang 212013, P. R. China \\ ' Institute of Theoretical and Computational Chemistry, Key Laboratory of Mesoscopic Chemistry of MOE, School \\ of Chemistry and Chemical Engineering, Nanjing University, Nanjing 210093, P. R. China \\ ${ }^{@ 1}$ Corresponding author E-mail: chenqy@ujs.edu.cn \\ ${ }^{\circledR 2}$ Corresponding authorE-mail: Liangxu@ujs.edu.cn
}

\begin{abstract}
A new BODIPY (4,4-difluoro-4-bora-3a,4a-diaza-s-indacene) was synthesized and investigated for photophysical and chemical properties based on donor-photoinduced electron transfer (d-PET) inhibition. Its sensing detection mechanism has been fluorescence turn-on involving d-PET blocking which was in-depth investigated by spectroscopy and electrochemistry, as well as by TD-DFT calculation. Strategically, d-PET was blocked by H-bonding from ethyl acetate and self-assembly of ВDPPHOH via $\mathrm{HO}$ - and $\mathrm{NO}_{2}$-fragments in $\mathbf{B D P P h O H}$.
\end{abstract}

Keywords: BODIPY, d-PET fluorescence, hydrogen bond, solvent turn-on.

\section{Влияние растворителя на флуоресценцию BODIPY с Аонорными (НО-) и акцепторными $\left(\mathrm{NO}_{2}^{-}\right)$заместителями}

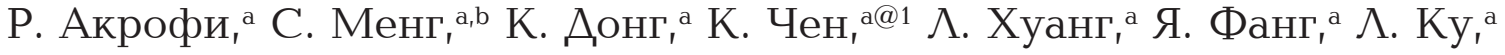 \\ К. Лианга@2 \\ а Университет Цзянсу, 212013 Чжэньизян, Китай \\ ${ }^{\mathrm{b}}$ Нанкинский университет, 210093 Нанкин, Китай \\ ${ }^{\circledR 1}$ E-mail: chenqy@ujs.edu.cn \\ ${ }^{\circledR 2}$ E-mail: Liangxu@ujs.edu.cn
}

В работе синтезирован новый BОDIPY (4,4-дифтор-4-бора-3а,4а-диаза-s-индацен), исследовань его фотофизические и химические свойства, ассочиированные с ингибированием донорно-фотоиндуиированного переноса электрона (d-PET). Его детектирование связано с «включением» флуоресиенции при блокировке d-PЕT, что было тщательно исследовано спектральными и электрохимическими методами, а также с привлечением TD-DFT расчетов. d-PET был намеренно блокирован при образовании водородных связей этилачетата и самосборки ВDРPНОН через $\mathrm{HO}-$ и $\mathrm{NO}_{2}$-группь в ВDPPhОН.

Ключевые слова: BODIPY, d-PET флуоресценция, водородная связь, влияние растворителя. 


\section{Introduction}

The design and synthesis of fluorescent chemosensors draws considerable attention because fluorescence-based detection methods are known for their simplicity and high sensitivity. ${ }^{[1]}$ BODIPY (4,4-difluoro-4-bora-3a,4a-diaza-sindacene) analogues have been fascinating class of molecules with potential applications in areas like biology, ${ }^{[2-8]}$ photodynamic therapy and chemosensors. ${ }^{[9-17]}$ The distinctive structural characteristics of nitro-BODIPY molecules are the electron donating and electron accepting chromophores in the same molecule by $\pi$-conjugation involving single or double bonds. BODIPY core of acceptor-BODIPY types, in contrast, are electron deficient owing to electron withdrawing substituents that takes electron by PET (photoinduced electron transfer) mechanism, ${ }^{[18,19]}$ which implies BODIPY core losing its fluorescing ability, the dilemma of nitrophenyl BODIPY and nitroarene dyes. ${ }^{[20,21]}$ Common but very unique strategy with several reports is the PET blocking electron transfer (ET) mechanism, which stops PET to acceptor in fluorophore-acceptor conjugates due to lowering energy of the fluorophore LUMO as consequent of intermolecular interactions. Electron-deficient functional group was introduced on the amino group to decrease energy level of the highest occupied molecular orbital (HOMO), and prevents its ET in the excited state of the fluorophore in a fluoranbased fluorescent probe via the strategy of blocking the intramolecular PET. This results in fluorescence recovery or light-ups of the fluorophore. In addition to PET-blocking as reviewed in the literature, another intramolecular strategy to turn-on or light up quenched fluorescence emission with several report are the solvent polarity, good H-bond donor and environment of a dye in the ground and excited states. ${ }^{[22-24]}$ Actually, the turn-on mechanism is almost similar to PET-blocking through solvent polarity association on the polar surfaces of the fluorophore at the excited state where PET is interrupted because of large dipolar moment of the fluorophore molecules and their interaction with the polar solvent molecules. ${ }^{[24]}$ Essentially, the solvent effects on the excited-state dynamics of fluorophores are vital to its photophysical and photochemical properties. Exploring solvent effects on excited-state dynamics enables one to understand the fluorescence properties. ${ }^{[25-27]}$ Report by Hu's group indicates that the nitrophenyl BODIPY remained quenched due to photoinduced electron transfer process from BODIPY to the acceptors. ${ }^{[28]}$ Contrary to their result in which little or no attention was given to solvent polarity and the environment of the BODIPY-nitrophenyl acceptor conjugate. Ethylacetate forms very strong $\mathrm{H}$-bonding with - $\mathrm{NO}_{2}$-arenes and nitroaniline crystals through $\mathrm{H}$-bonding utilizing their dipoles or the polarizability. ${ }^{[29]}$ To develop the hyperchromic and the bathochromic solvent turn-on dyes, we report a donor hydroxy-benzyl substituent at 2-position for compound BDPPhOH (Scheme 1). The design involves modification to the 2-position with donor group on the BODIPY core in consideration of the fluorophore interaction in a range of polar environment at the excited state to enable high hyperchromic shift. The donor hydroxyl $(\mathrm{OH})$ of BDPPhOH interact with acceptor $\left(\mathrm{NO}_{2}\right)$ through aggregation induced blocking $\mathrm{PET}$ in petroleum ether (PE), ethyl acetate (EA) with high fluorescence turn-ON. The spectroscopic and electrochemical analysis/measurement was done to ascertain hydrogen-bonding mediation blocking PET process to turn the fluorescence on.

\section{Experimental}

Synthesis of (4-(5,5-difluoro-1,3,7,9-tetramethyl-10-(4nitrophenyl)-5H-4l4,5l4-dipyrrolo [1,2-c:2', 1'-f][1,3,2] diazaborinin-2-yl)phenyl)methanol (BDPPhOH). To a solution of 5,5-difluoro-1,3,7,9-tetramethyl-10-(4-nitrophenyl)-5H-414,514dipyrrolo[1,2-c:2',1'-f][1,3,2]diazaborinine (A, $189.342 \mathrm{mg}, 0.513$ $\mathrm{mmol})$ in $\mathrm{CH}_{2} \mathrm{Cl}_{2}(30 \mathrm{~mL})$ was added 1-iodopyrrolidine-2,5-dione ( $N$-iodosuccinimide) $(76.947 \mathrm{mg}, 0.5 \mathrm{mmol})$. The reaction mixture was stirred at room temperature for $1 \mathrm{~h}$. After addition of a saturated $\mathrm{NaCl}$ solution, the aqueous layer was extracted 3 times with $\mathrm{CH}_{2} \mathrm{Cl}_{2}$. The organic layer combined was dried over anhydrous $\mathrm{Na}_{2} \mathrm{SO}_{4}$, filtered, and concentrated under vacuum pressure. The crude product $\mathrm{B} 1$ was obtained. Next, the crude product B1 (300 $\mathrm{mg}, 0.10 \mathrm{mmol})$ in toluene $(20 \mathrm{~mL})$ was mixed with (4-(hydroxymethyl)phenyl)boronic acid (189.342 $\mathrm{mg}, 0.423 \mathrm{mmol})$ in ethanol (10 $\mathrm{mL}$ ), and then $\mathrm{K}_{2} \mathrm{CO}_{3}(42 \mathrm{mg}, 0.3 \mathrm{mmol}), \mathrm{Pd}\left(\mathrm{PPh}_{3}\right)_{4}(0.005 \mathrm{mmol}$, $6.0 \mathrm{mg}$ ) were added. The mixture was put under a $\mathrm{N}_{2}$ atmosphere refluxing for $8 \mathrm{~h}$. After removal of the solvent under reduced pressure, the mixture was purified by column chromatography (silica gel, DCM) to give BDPPhOH. Yield: $60 \%$. ${ }^{1} \mathrm{H}$ NMR (400 MHz, $\delta_{\mathrm{H}}$ ppm: $8.39(\mathrm{~d}, J=8.2 \mathrm{~Hz}, 2 \mathrm{H}), 7.58(\mathrm{~d}, J=8.2 \mathrm{~Hz}, 2 \mathrm{H}), 7.39(\mathrm{~d}$, $J=7.7 \mathrm{~Hz}, 2 \mathrm{H}), 7.12$ (d, $J=7.7 \mathrm{~Hz}, 2 \mathrm{H}), 6.04$ (s, 1H), 4.72 (s, 2H),

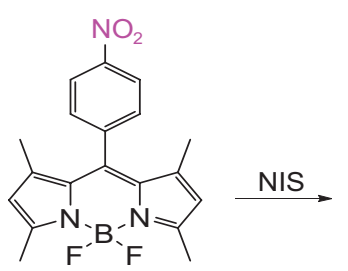

A

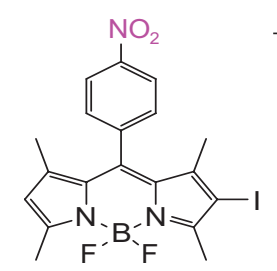

B1
Suzuki-Miyaura

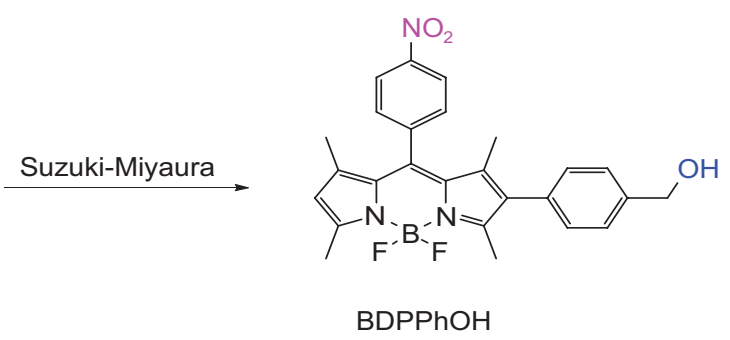

$\mathrm{BDPPhOH}$

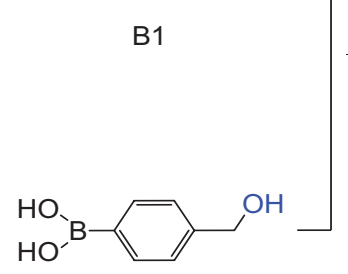

Scheme 1. The synthesis route of BDPPhOH. 
$3.48(\mathrm{~s}, 1 \mathrm{H}), 2.59$ (s, 3H), 2.51 (s, 3H), 1.37 (s, 3H), 1.27 (s, 3H). ${ }^{13} \mathrm{C}$ NMR (101 MHz, $\left.\mathrm{CDCl}_{3}\right) \delta_{\mathrm{C}}$ ppm: 156.97, 155.28, 148.40, 142.67, $142.15,139.95,138.55,138.43,133.99,132.53,130.94,130.24$, $129.73,127.11,124.43,122.08,65.04,14.76,14.70,13.43,13.01$.

\section{Results and Discussion}

\section{Synthesis and Characterizations}

BDPPhOH was prepared by Suzuki Miyaura-cross coupling of B1 and 4-hydroxymethylphenyl boronic acid in the presence of $\mathrm{Pd}\left(\mathrm{PPh}_{3}\right)_{4}$ (Scheme 1). The BDPPhOH was characterized by ${ }^{1} \mathrm{HNMR}$ (Figure S1, see ESI), ${ }^{13} \mathrm{CNMR}$ (Figure S2, see ESI) and mass spectrometric analyses (Figure S3, see ESI). The intense molecular ion peak of BDPPhOH showed at the $m / z=474.26$ (Calcd. [M-H] ${ }^{-}=$ 474.30) confirming compound BDPPhOH. The maximum UV-Vis absorption of BDPPhOH in $\mathrm{CH}_{2} \mathrm{Cl}_{2}$ (DCM) was at $518 \mathrm{~nm}$ (Table 1). The emission wavelength of compound BDPPhOH was $542 \mathrm{~nm}$ (Figure 1).

\section{Effect of Solvent on the Fluorescent Properties}

Fluorescence analysis of BDPPhOH was initially recorded in four different solvents (dichloromethane (DCM), ethylacetate (EA), methanol $(\mathrm{MeOH})$ and tetrahydrofuran (THF)) and spectral changes were plotted (Figure 1). The high fluorescence light-up (turn-on) in THF and EA was anomaly observed compared to the low fluorescence intensity recorded in DCM. The fluorescence of nitrophenyl BODIPY(s) from literature is reported as photo-induced electron transfer quenched compounds. ${ }^{[27]}$ Hence, it was not a surprise they have low fluorescence in DCM. But what was unknown was the second novelty, the hyperchromic and the bathochromic solvent turn-on in EA and THF in particular. This suggests in simple terms the solvotochromic effect on the PET process of electron flow from the HOMO of donor BODIPY core via the conjugated phenyl spacer to the LUMO of the acceptor nitro-substituent. At first was merely, thought of as the polar solvent effect on the BDPPhOH. However, the spectroscopic analysis in $\mathrm{MeOH}$ and other more polar solvent disproved the observations. A fresh spectroscopic analysis for four more solvents, from low, medium to high polarity in addition to the earlier once was used in recording the spectra for BDPPhOH (Table 1).

The results were reproducible in the four solvents from the repeated experiments and the low fluorescence intensities in acetone, acetonitrile, ethylene glycol but a very high fluorescence enhancement in fourth solvent (PE, EA, THF and DMSO) were additionally observed. Petroleum (PE) sparingly dissolves the compounds producing suspended solid particles in solution. The fluorescence intensity in EA (815) is found to be 33 times higher than that of DCM (25). Similarly, in THF, BDPPhOH recorded very high enhancement at wavelength of $551 \mathrm{~nm}$ and the fluorescence dimension ranged from 520-650 nm compared to DCM. The spectroscopic analysis for BDPPhOH in DCM-solvents showed increasing fluorescence intensity from DCM, the lowest via $\mathrm{MeOH}$ to THF but a big anomaly occurred in EA with high hyperchromic shift, which possibly was not only because of large dipole polar moment because methanol and THF are more polar than EA. The high turn on could have been due to AIEE (aggregate induced emission enhancement) and the environment of the two fluorophores.

\section{$\triangle G_{P E T}$ Confirmation of PET}

The donor hydroxyl $(\mathrm{OH})$ of BDPPhOH might donate electron to the acceptor $\left(\mathrm{NO}_{2}\right)$ in a self-assembly aggregation PET blocking in EA, increasing fluorescence emission intensity via AIEE. The high intensity, or quantum yield in EA is explained from environment effect of solvent polarity at the excited state of the fluorophores and their large dipole moment which interact with polar solvent molecule. The relaxation or reorientation shifting to lower energy that turns on fluorescence exponentially, inhibiting PET. The LUMO of acceptor is low lying than the LUMO of the BODIPY core in BDPPhOH. Electron transfer therefore occurs from the fluorophore core to the acceptor, the nitrophenyl moiety. This is oxidative photoinduced electron transfer (d-PET). In a turn-on, fluorescence titration of BDPPhOH (DCM) with increasing amount of ethyl acetate (EA), the fluorescence intensity was enhanced at $548 \mathrm{~nm}$ with red shift of BDPPhOH for $8 \mathrm{~nm}$ (Figure 2, Table 1), which suggests d-PET-blocking and confirms the theoretical DFT calculations. PET driving force is determined by the

Table 1. Spectroscopic data in the eight different solvents for BDPPhOH.

\begin{tabular}{lccc}
\hline \multicolumn{1}{c}{ Solvent (v:v) } & Emission $(\mathrm{nm}) /$ Intensity & Absorption (nm)/ Intensity & $\varepsilon\left(\mathrm{mol} / \mathrm{cm}^{3}\right)$ \\
\hline PE - DCM (12:1) & $546 / 789$ & $519 / 2.27$ & 45318 \\
\hline Acetone - DCM (12:1) & $545 / 50$ & $517 / 2.37$ & 47396 \\
THF - DCM (12:1) & $551 / 766$ & $520 / 2.39$ & 47774 \\
MeOH - DCM (12:1) & $541 / 32$ & $513 / 2.35$ & 47074 \\
EA - DCM (12:1) & $548 / 815$ & $518 / 2.35$ & 47020 \\
CH CN - DCM (12:1) & $545 / 50$ & $515 / 2.21$ & 44328 \\
DMSO & $556 / 650$ & $520 / 2.38$ & 47784 \\
E- DCM (12:1) & $543 / 33$ & $518 / 2.02$ & 40348 \\
DCM & $542 / 25$ & $518 / 2.37$ & 47324 \\
\hline
\end{tabular}

Note: The slit is 5 at PMT 600. Excitation wavelength is $518 \mathrm{~nm}$. Ethylene glycol = E, Ethyl acetate $=\mathrm{EA}$. 

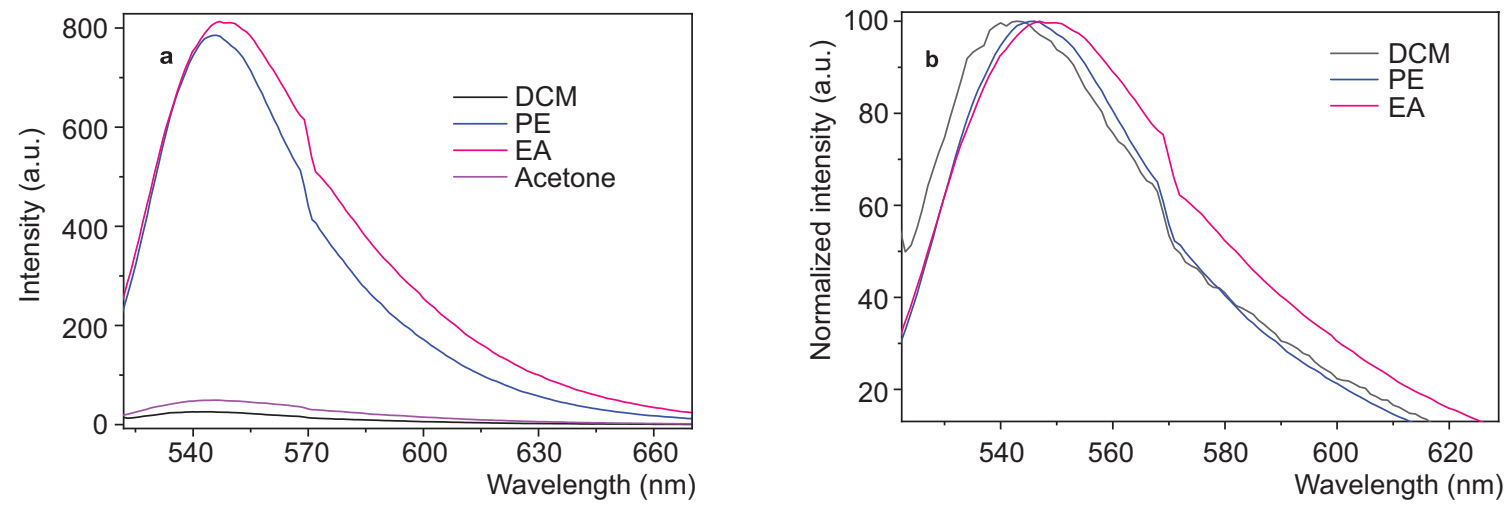

Figure 1. Fluorescence spectra of BDPPhOH $(2 \mu \mathrm{M})$ in solvents. (a) DCM, PE, and EA; (b) normalized emission maxima in DCM, PE, and EA, with excitation and emission slits of $5 \mathrm{~nm}$ in all. Solvents ratio to DCM solution of BDPPhOH is 1:12.
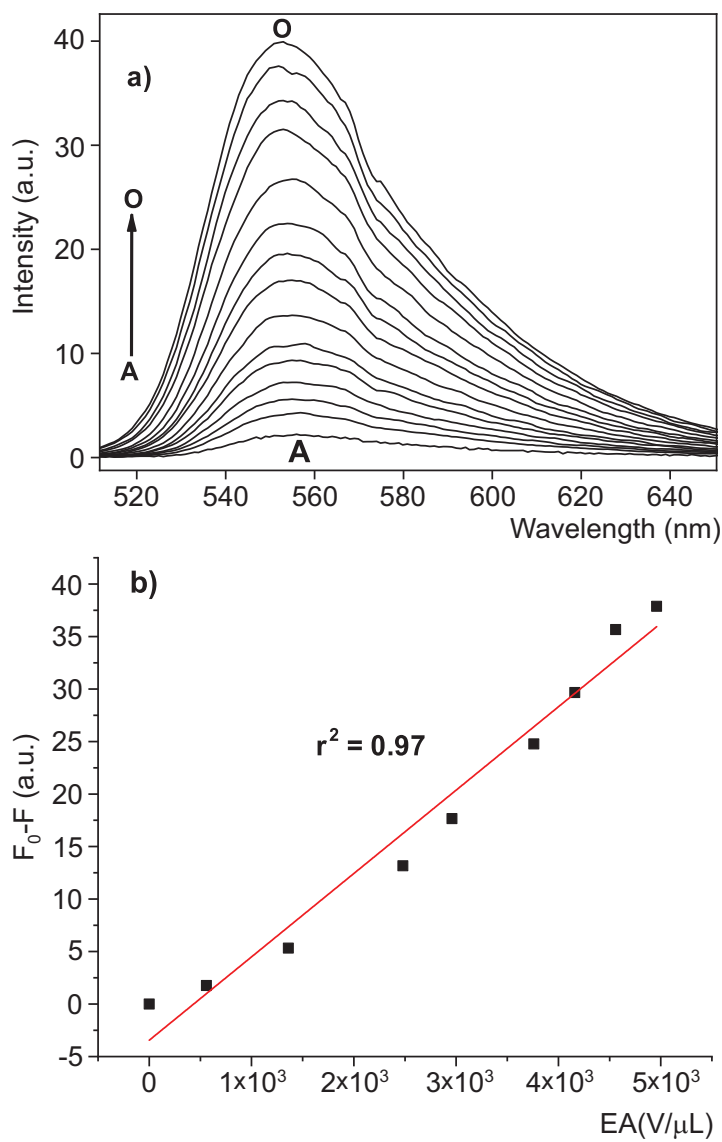

Figure 2. (a) Changes of the emission spectra of BDPPhOH $\left(2.0 \cdot 10^{-6} \mathrm{M}\right)$ in DCM with different equivalents of $\mathrm{EA}$ (A to $\mathrm{O}$ : in ratio 1.0 to 20 eq. where $\mathrm{A}=65 \mu \mathrm{L}, \mathrm{B}=130 \mu \mathrm{L} \ldots \mathrm{O}=1300 \mu \mathrm{L}$ (EA/DCM, v/v 1:3.1 at total volume $5.3 \mathrm{~mL}$ ); excited at 481 $\mathrm{nm}(\mathrm{Ex}$ and Em slit at $5 \mathrm{~nm}$ at $\mathrm{PMT}=600 \mathrm{~V})$ and (b) linear relationship of the BDPPhOH in DCM and EA at emission wavelength of $547 \mathrm{~nm}$ with $\mathrm{r}^{2}=0.97$.

thermodynamic data in the free energy change. This free energy change must be negative to confirm PET which is described by Rehm-Weller's equation. ${ }^{[29]}$

$$
\Delta G_{\mathrm{PET}}=E_{\mathrm{ox}}(D)-E_{\mathrm{red}}(A)-E_{\mathrm{red}}-\mathrm{C}
$$

From above equation, the free energy change, $\Delta G_{\mathrm{PET}}$ of BDPPhOH is calculated from the cyclic voltammogram (CV) data, excitation energy of the BDPPhOH obtained from DFT calculation, oxidation potential $\left(E_{\mathrm{ox}}\left(\mathrm{D} / \mathrm{D}^{+}\right)\right.$is the ground-state oxidation potential of the donor) and reduction potential $\left(E_{\mathrm{red}}\left(\mathrm{A} / \mathrm{A}^{-}\right)\right.$is the ground-state reduction potential of the acceptor) for $\mathbf{B D P P h O H}$, while $\mathrm{C}$ is an electrostatic interaction term (constant) $(0.06 \mathrm{eV}) .{ }^{[2]}$ The $\Delta G_{\mathrm{PET}}$, for BDPPhOH are -0.2249 and -0.0151 confirming PET in the singlet state and the parameters for free energy change are shown in Table 2. The DFT for the monomer suggests intramolecular charge transfer from fluorophore core to the nitrophenyl conjugate of BDPPhOH.

Table 2. Parameter for the free energy change.

\begin{tabular}{lc}
\hline$E_{\mathrm{ox}}(\mathrm{D})$ & $1.32 \mathrm{~V}$ \\
$E_{\mathrm{red}}(\mathrm{A})$ & $-0.88,-1.12 \mathrm{~V}$ \\
$E_{\mathrm{s}}$ excitation energy & $2.3649 \mathrm{eV}$ \\
$\mathrm{C}$, constant & $0.06 \mathrm{eV}$ \\
$\Delta G_{\mathrm{PET}}$ & -0.2249 and -0.0151 \\
\hline
\end{tabular}

PET can occur easily from the BODIPY core to the $\mathrm{NO}_{2}$-phenyl in the BDPPhOH due to the strong electron withdrawing acceptor. The occurrence of PET in compound is supported by the HOMO/LUMO calculation (Figure S4, see ESI). The BDPPhOH HOMO and LUMO are calculated by DFT method using Gaussian09 on the B3LYP/6-311g level. ${ }^{[30,31]}$ For the monomer (2), the 2-HOMO is localized on the BODIPY core and partially on benzyl alcohol substituent while the 2-LUMO+1 is located on both the nitrophenyl moiety and BODIPY core at excitation. In the monomer (1), however, the 1-HOMO is partially located on the BODIPY-core and 1-LUMO highly localized on the nitro-phenyl (Figure S5, see ESI). For the dimeric BDP$\mathbf{P h O H}$, both the 2-HOMO-2 and 2-LUMO+2 are localized on the BODIPY core following intermolecular interaction via $\mathrm{H}$-bonding and high fluorescence light-up (Figures 3 and 4). To understand the experimental results, the geometries of BDPPhOH and its possible dimers were optimized using $\mathrm{B} 3 \mathrm{LYP} / 6-31 \mathrm{G}^{* *}$ method, and the electrostatic potentials 
1-LUMO

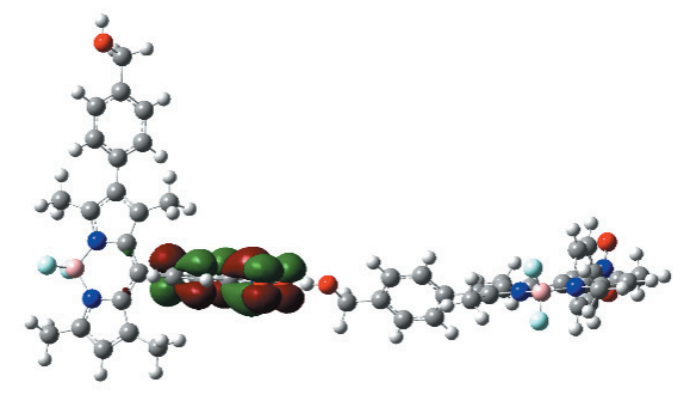

1-HOMO

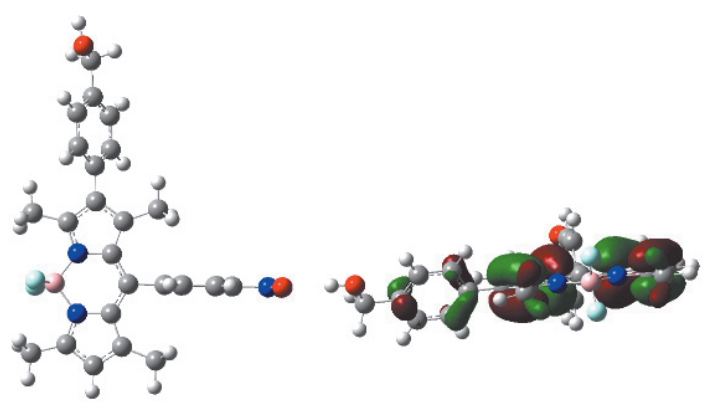

2-LUMO+2

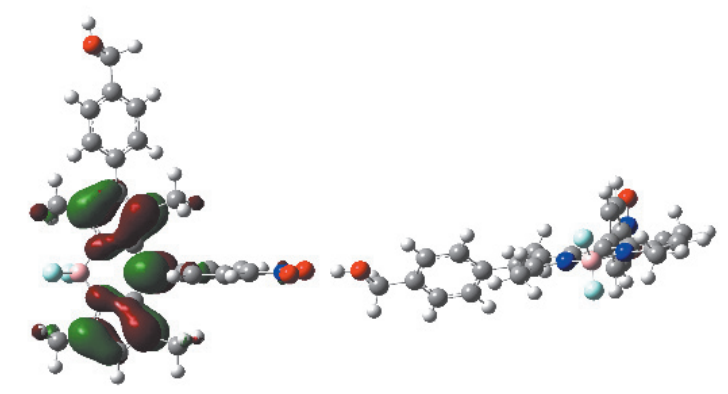

3-HOMO-2

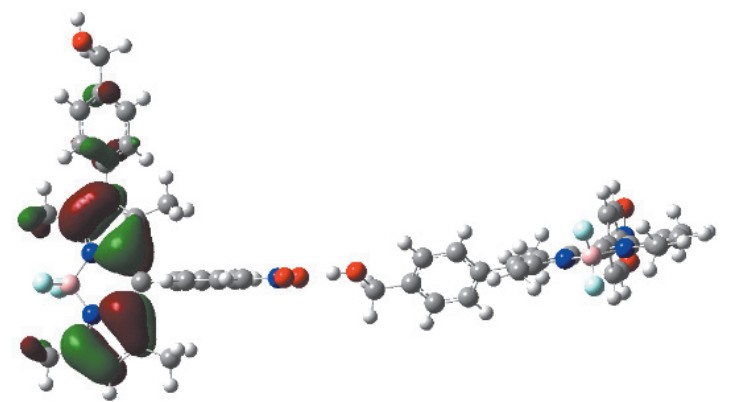

Figure 3. HOMO and LUMO of dimeric BDPPhOH compound via intermolecular H-bonding in DFT calculation. The molecular orbitals are obtained through DFT calculations at the B3LYP/6-31G $\mathrm{G}^{* *}$ level.

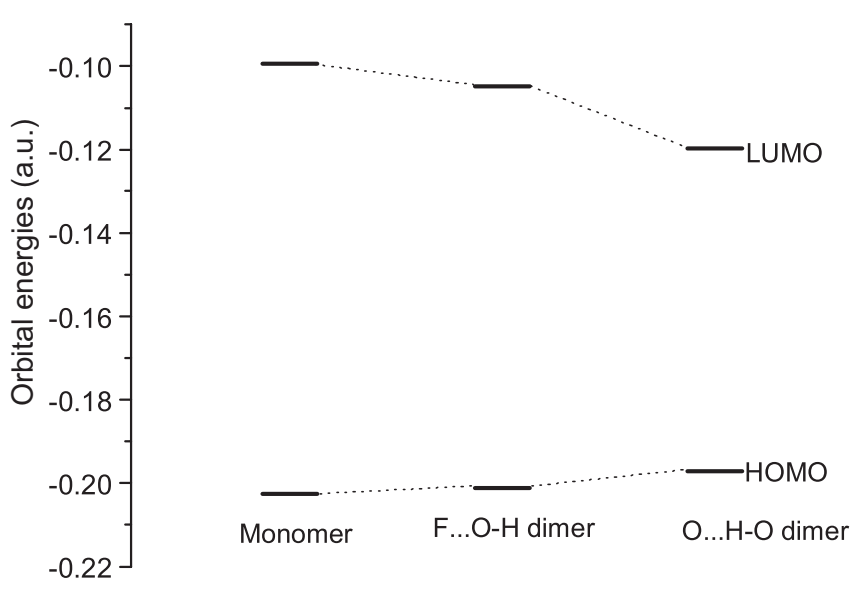

Figure 4. The frontier molecular orbital energies of BDPPhOH monomer and the F $\cdots \mathrm{H}-\mathrm{O}$ and $\mathrm{O} \cdots \mathrm{H}-\mathrm{O}$ dimers, calculated by $\mathrm{B} 3 \mathrm{LYP} / 6-31 \mathrm{G}^{* *}$ method in relation to EA.

(ESP) of monomer were then calculated at the same level. The interaction energies correspond to the energy difference between the isolated molecules. The basis set superposition error (BSSE) was corrected by the counterpoise method. ${ }^{[31,32]}$ From the molecular structure of BDPPhOH and its electrostatic potential map in Figure S5, it can be seen that the polar groups such as $-\mathrm{NO}_{2},-\mathrm{BF}_{2}$, and $-\mathrm{OH}$ are evenly distributed in the molecular backbone. This is beneficial to the formation of self-aggregation for BDPPhOH in solutions. To illustrate the influence of self-aggregation on the electronic structures of BDPPhOH in solution, the geometries of the $\mathrm{O} \cdots \mathrm{H}-\mathrm{O}$ dimer as well as $\mathrm{F} \cdots \mathrm{H}-\mathrm{O}$ dimer in the gas phase were optimized through the DFT method at the B3LYP/6-31G ${ }^{* *}$ level, respectively. The intermolecular distances $\mathrm{O} \cdots \mathrm{H}-\mathrm{O}(\mathrm{rO} \cdots \mathrm{H})$ and $\mathrm{F} \cdots \mathrm{H}-\mathrm{O}(\mathrm{rF} \cdots \mathrm{H})$ interactions between two BDPPhOH molecules are $2.02 \AA$ and $1.84 \AA$, respectively, which are much less than the sum of the van der Waals radii $(\mathrm{O}+\mathrm{H}: 2.72 \AA ; \mathrm{F}+\mathrm{H}: 2.67 \AA)$. And the intermolecular interaction of $\mathrm{O} \cdots \mathrm{H}-\mathrm{O}$ dimmer and $\mathrm{F} \cdot \mathrm{H}-\mathrm{O}$ dimer is -4.36 and $-5.23 \mathrm{kcal} / \mathrm{mol}$, respectively. That indicates the significant self-aggregation can exist for BDPPhOH in different solutions.

\section{Cyclic Voltammetry (CV) Analysis}

The current voltage curve obtained by cyclic voltammetry (CV) and differential pulse voltammetry (DPV) showed two reduction processes and one oxidation process in $\mathrm{CH}_{2} \mathrm{Cl}_{2}$ containing $0.1 \mathrm{M}$ TBAP (Figures $5 \mathrm{a}$ and $5 \mathrm{~b}$ ). The half-wave potential located at $E_{1 / 2}=-0.88$ and $-1.12 \mathrm{~V}$. The first reduction at $-0.88 \mathrm{~V}$ is BODIPY centered electron transfer while the second at $-1.12 \mathrm{~V}$ is located at the linked $\mathrm{PhNO}_{2}$ group. ${ }^{[33]}$ A reversible oxidation at $E_{1 / 2}=1.45 \mathrm{~V}$ was also observed and assigned as the BODIPY centered electron transfer. Both the first reduction and first oxidation potentials of BODIPY are positively shifted as compared with the none- $\mathrm{NO}_{2}$ substituted BODIPY complexes with $E_{1 / 2}=-1.24 \mathrm{~V}$ for first reduction and $E_{1 / 2}=1.21 \mathrm{~V}$ for first oxidation. ${ }^{[34]}$ This potential shift is consistent with the strong electron withdrawing effect of $\mathrm{NO}_{2}$ group. Uniform reversibility was also obtained by varying the scan rates from 100 to $600 \mathrm{mV} \mathrm{s}^{-1}$ as shown in Figure $5 \mathrm{c}$ indicating that the cation or anion radical formed upon oxidation or reduction are stable 

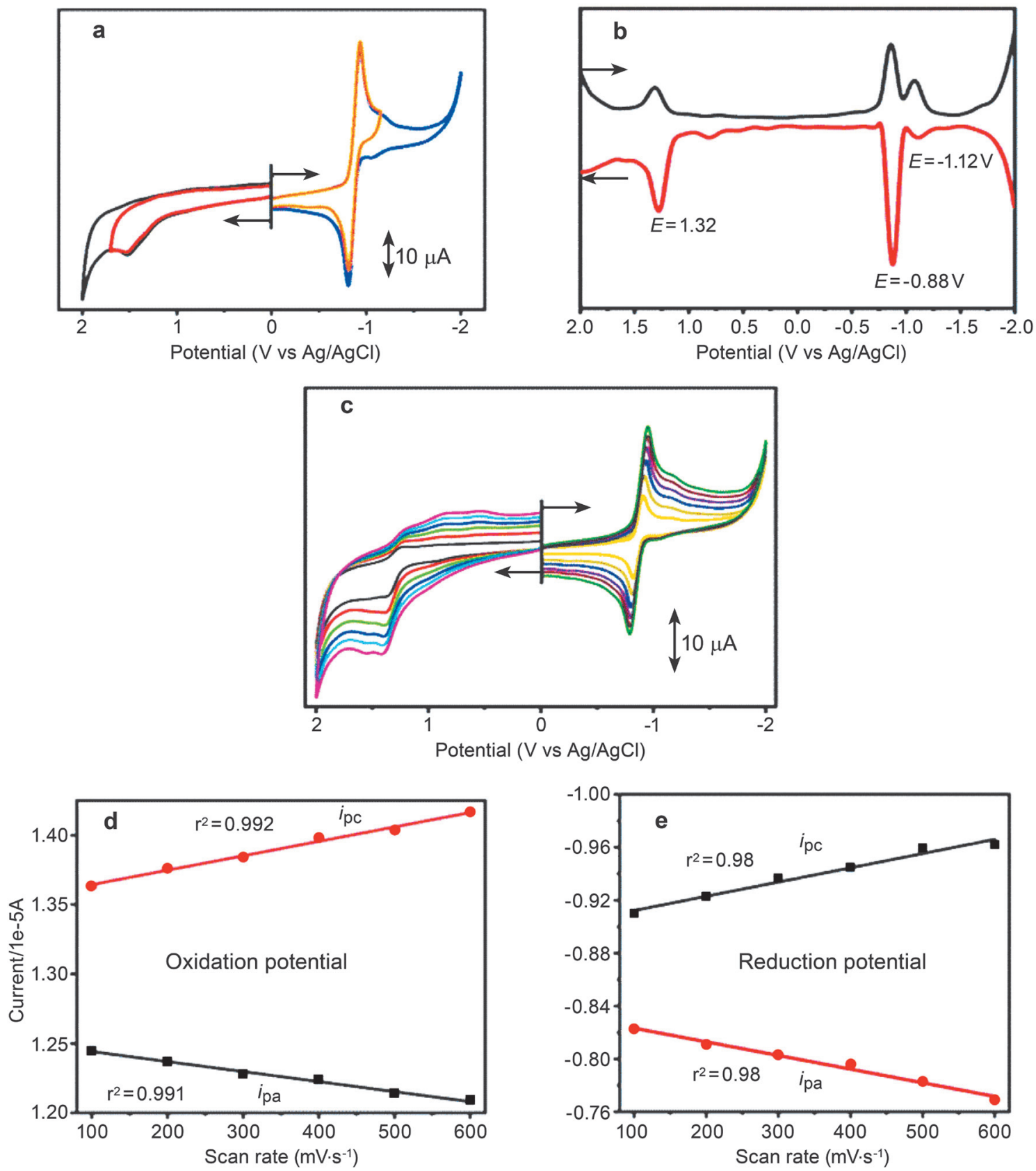

Figure 5. Electrochemical responses showing (a) CV curves; (b) DPV curves and (c) Scan rates from 100 to $600 \mathrm{mV} \mathrm{s}^{-1}$ for BDPPhOH (2 $\mathrm{mg}$ ). Plots of anodic and cathodic currents at different scan rates for both (d) oxidation and (e) reduction potentials. Conditions: $50 \mathrm{mV} \mathrm{s}^{-1}$ scan rate (in exceptions of $\mathrm{d}$, e and f), at $25^{\circ} \mathrm{C}$, solvent: $\mathrm{CH}_{2} \mathrm{Cl}_{2}$ in $0.1 \mathrm{M}$ TBAP.

at the CV timescale. The peak current $\left(i_{\mathrm{pa}}\right.$ or $\left.i_{\mathrm{pc}}\right)$ obtained for both reduction and oxidation potentials at various scan rates indicates a linear correlation with $\mathrm{R}^{2}=0.9$ (Figures $5 \mathrm{~d}$ and $5 \mathrm{e}$ ) and confirms that both the oxidation and reduction processes are based on diffusion-controlled mechanism.

\section{d-PET-Blocked Emission Mechanism}

At photoexcited state, the LUMO of fluorophore does not donate electrons to the acceptor because it's lower than the acceptor in EA. The LUMO of EA is higher and donate electron to low-lying LUMO of acceptor due to H-bonding. Simultaneously, EA donate electron to the LUMO of the acceptor (Scheme 2). BDPPhOH in the BODIPY core undergo rapid radiative decay from the singlet state to their ground state losing energy in the form of fluorescence. Turn on occur. Oxidation and reduction halves are formed by PET in DCM but have no peaks to show in EA because of no PET, no oxidation and reduction halves potentials. This explains why the peaks of oxidation half and the reduction half of BDPPhOH are diminishing at the gradual addition of EA to the DCM solutions of BDPPhOH (Figure S6, see ESI).

The high fluorescence in $\mathrm{PE}$ is explained from aggregate induced enhance emission, due to the solid nano particle observed from the PE solution of BDPPhOH. Therefore, the fluorescence emission of BDPPhOH in PE is merely due to AIEE aggregate via PET-blocking which turn-on fluorescence but no colorimetric as shown in EA. 


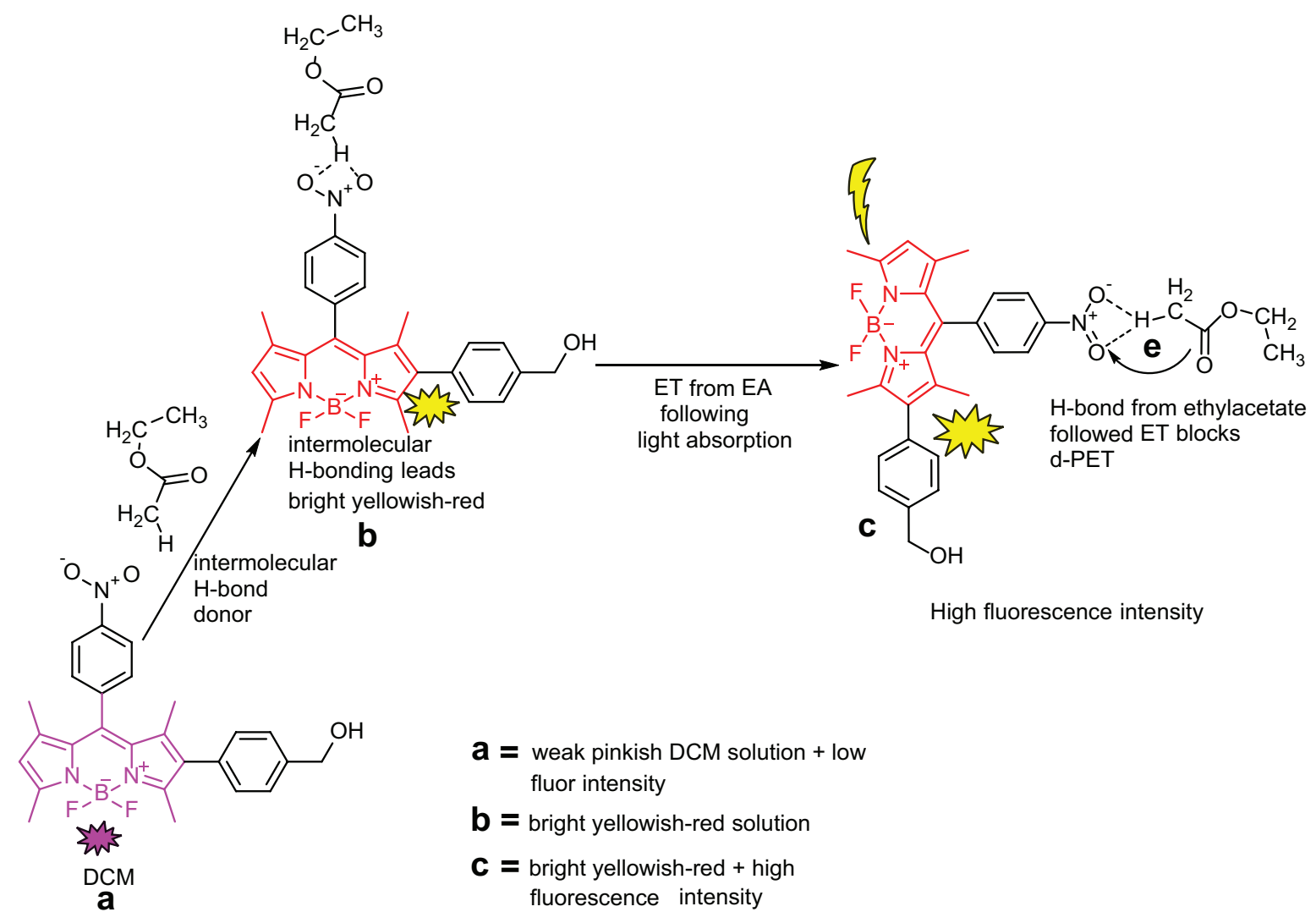

Scheme 2. BDPPhOH oxidative PET electron transfer mechanism for the donor and acceptor and fluorescence turn-ON in ethylacetate.

THF also follows the hyperchromic and bathochromic trend with red shift of $551 \mathrm{~nm}$. The fluorescence enhancement in EA and THF apart from PE, therefore suggest pure interruption in the PET process involving the electron migration from the HOMO to the LUMO at the molecular level. From the spectroscopic analysis, all the polar solvents suspected to have the influence to inhibit or stop the PET process by their intermolecular electron transfers in the molecular environment of the photoexcited state. These argue that, the interruption of PET process perhaps, could be attributive to hydrogen bonding from a donor. Literature survey confirms, which is explained by the mechanism of the PETblocking process. Are EA and THF H-bond donors? And are there reports to this effect? To answer that, literature and DFT calculation speak to that effect. DFT has optimized hydrogen-bonded $\mathrm{O} \cdots \mathrm{H}-\mathrm{O}$ and $\mathrm{F} \cdot \mathrm{H}-\mathrm{O}$ dimers of the BDPPhOH (Figure S7, Tables S1 and S2, see ESI). Fascinatingly, the donor - H-bond supplies the needed electron for the nitro group through the H-bonding interaction interrupting the PET from the BODIPY core in BDPPhOH, demonstrating fluorescence turn-ON (Scheme 2). The lights-up fluorescence emission of the BDPPhOH in EA or THF is because of the strong intermolecular interaction of EA or THF with BDPPhOH (Scheme S1). The ability of EA to solvate and change color even under visible light condition in the ground state is attributed to its ester $\left(-\mathrm{COOCH}_{2}-\right)$ functionality. The immediate change in color of BDPPhOH upon addition of ethylacetate is its complex solution formed via the strong hydrogen bonding between the ester group and the nitro $\left(\mathrm{NO}_{2}\right)$ of nitrophenyl substituent. In the excited state, strong intermolecular interaction leading to hydrogen bonding, coupled with polar solvent environment, probably, surrounds the electron deficient nitro-group in the radical state with negative charges which interrupts the electron migration from donor-BODIPY core to the nitro-acceptor substituent in the BDPPhOH. The solvent reorientation and relaxation to lower energy state with the fluorophore results in high hyperchromic shift (high quantum yield). The high fluorescence intensity observed in EA compared to the other solvents is perhaps due to the non-bonding electron of $\mathrm{NO}_{2}-$ phenyl group bonding to the hydrogen atom of the solvent forming a stable hydrogen-bonded complex. Therefore, BDPPhOH is a turn-on sensor for EA for its colorimetric change from dull light pinkish color to bright red orange.

\section{Conclusions}

A new D-A conjugated BDPPhOH dye was synthesized and investigated for their PET inhibition. The spectroscopic investigation showed increasing fluorescence intensity; from the lowest in DCM and a big anomaly in EA, THF, PE with high hyperchromic shift. The high turn on could be due to AIE and the environment of the fluorophores. The relaxation or reorientation shift to lower energy that turns on fluorescence exponentially, inhibiting PET. The AIEE was initiated by interaction of donor $(\mathrm{OH})$ in $\mathbf{B D P P h O H}$ with the acceptor $\left(\mathrm{NO}_{2}\right)$ conjugate in self-assembly aggregation inhibiting PET. Our results demonstrate that, the donor $(\mathrm{OH})$ on the BODIPY core interacting with acceptor $\left(\mathrm{NO}_{2}\right)$ 
conjugates can be new kind of solvents turn-on fluorescence dyes based on d-PET-blocked emission.

Acknowledgements. This work was financially supported by the National Natural Science Foundation of China (21571085, 21701056 and 21701058).

Appendix A. Supplementary data, detailed experimental procedures, Figure S1 to Figure S7, Scheme S1, Table S1, Table S2 and chemical structure to this article to this article can be found online at https://macroheterocycles.isuct.ru/ en/mhc200606c.

\section{References}

1. Hu W., Liu M., Zhang X.F., Wang Y., Wang Y., Lan H., Zhao H. J. Phys. Chem. C 2019, 123, 15944-15955.

2. Guo Z., Park S., Yoon J., Shin I. Chem. Soc. Rev. 2014, 43, $16-29$.

3. Zhang P.L., Wang Z.K., Chen Q.Y., Du X., Gao J. Bioorg. Med. Chem. Lett. 2019, 29, 1943-1947.

4. Jiang G., Wang J., Yang Y., Zhang G., Liu Y., Lin H., Zhang G., Li Y., Fan X. Biosens. Bioelectron. 2016, 85, 62-67.

5. Antina E.V., Bumagina N.A., V'yugin A.I., Solomonov A.V. Dyes Pigm. 2017, 136, 368-381.

6. $\quad$ Li Z., Zhu Z.Z., Shu Z.W., Ding J., You J.M. Sens. Actuators $B$ Chem. 2019, 282, 541-548.

7. He S.J., Xie Y.W., Chen Q.Y. Spectrochim. Acta. A Mol. Biomol. Spectrosc. 2018, 195, 210-214.

8. Turksoy A., Yildiz D., Akkaya E.U. Coord. Chem. Rev. 2019, 379, 47-64.

9. Boens N., Verbelen B., Ortiz M.J., Jiao L.J., Dehaen W. Coord. Chem. Rev. 2019, 399, 213024-85.

10. Kamkaew A., Lim S.H., Lee H.B., Kiew L.V., Chung L.Y., Burgess K. Chem. Soc. Rev. 2013, 42, 77-88.

11. He L., Dong B., Liu Y., Lin W. Chem. Soc. Rev. 2016, 45, 644-6461.

12. Lu W.L., Lan Y.Q., Xiao K.J., Xu Q.M., Qu L.L., Chen Q.Y., Huang T., Gao J., Zhao Y. J. Mater. Chem. B 2017, 5, 1275-1283.

13. Jung H.S., Chen X., Kim J.S., Yoon J. Chem. Soc. Rev. 2013, 42, 6019-6031.

14. Erbas-Cakmak S., Kolemen S., Sedgwick A.C., Gunnlaugsson T., James T.D., Yoon J., Akkaya E.U. Chem. Soc. Rev. 2018, 47, 2228-2248.
15. Xu X.L., Shao J., Chen Q.Y., Li C.H., Kong M.Y., Fang F., Ji L., Boison D., Huang T., Gao J., Feng C.J. J. Inorg. Biochem. 2016, 159, 1-6.

16. Lan H., Liu B., Lv G., Li Z., Yu X., Liu K., Cao X., Yang H., Yang S., Yi T. Sens. Actuators B Chem. 2012, 173, 811816.

17. Zhang P.L., Shao J., Li X.T., Chen Q.Y., Qu L.L. Anal. Methods 2019, 11, 827-831.

18. Huang K., He S., Zeng X. Tetrahedron Lett. 2017, 58 , 2004-2008.

19. Velmurugan K., Prabhu J., Raman A., Duraipandy N., Kiran M.S., Easwaramoorthi S., Tang L., Nandhakumar R. ACS Sustain. Chem. Eng. 2018, 6, 16532-16543.

20. Mishra A., Lee S., Kim H., Cook T.R., Stang P.J., Chi K.W. Chem. Asian. J. 2012, 7, 2592-2599.

21. Jean-Gérard L., Vasseur W., Scherninski F., Andrioletti B. Chem. Commun. 2018, 54, 12914-29.

22. Zhang Y.L., Jiang M.J., Han G.C., Zhao K., Zhong B., Kam T., Wong S. J. Phys. Chem. C 2015, 119, 27630-27638.

23. Lee H.J., Jana J., Ngo Y.T., Wang L.L., Chung J.S., Hur S.H. Mater. Res. Bull. 2019, 119, 110564.

24. Shaikh M., Mohanty J., Singh P.K., Bhasikuttan A.C., Rajule R.N., Satam V.S., Bendre S.R., Kanetkar V.R., Pal H. J. Phys. Chem. A 2010, 114, 4507-4519.

25. Narang U., Zhao C.F., Bhawalkar J.D., Bright F., Prasad P.N. J. Phys. Chem. 1996, 100, 4521-4525.

26. Legaspi C.M., Stubbs R.E., Yaron D.J., Linda A., Kemboi A., Fossum E., Lu Y., Zheng Q., Rothberg L.J.C. J. Phys. Chem. C 2018, 122, 11961-11972.

27. Finckh P., Weeren S., Pollinger F. J. Phys. Chem. 1989, 93, 5173-5179.

28. Hu R., Lager E., Liu J., Lam J.W.Y., Sung H.H.Y., Williams I.D., Zhong Y., Wong K.S. J. Phys. Chem. C 2009, 113, $15845-15853$

29. Wang S., Cai J., Sadygov R., Lim E.C. J. Phys. Chem. 1995, 99, 7416-7420.

30. Frisch M.J., Trucks G.W., Schlegel H.B. et al. Gaussian, Inc. 2009.

31. Simon S., Duran M., Dannenberg J.J. J. Chem. Phys. 1996, 105, 11024-11031.

32. Boys S.F., Bernardi F. Mol. Phys. 1970, 19, 553-566.

33. Fang Y.Y., Jiang X.Q., Ou Z.P., Michelin C., Desbois N., Gros C.P., Kadish K.M. J. Porphyrins Phthalocyanines 2014, 18, 832-841.

34. Tao J.Y., Sun D., Sun L., Li Z.Z., Fu B., Liu J., Zhang L., Wang S.F., Fang Y.Y., Xu H.J. Dyes Pigm. 2019, 168, 166-174.

Received 06.06.2020 Accepted 28.09.2020 